\title{
Development of coatings for ultrasonic additive manufacturing sonotrode using laser direct metal deposition process
}

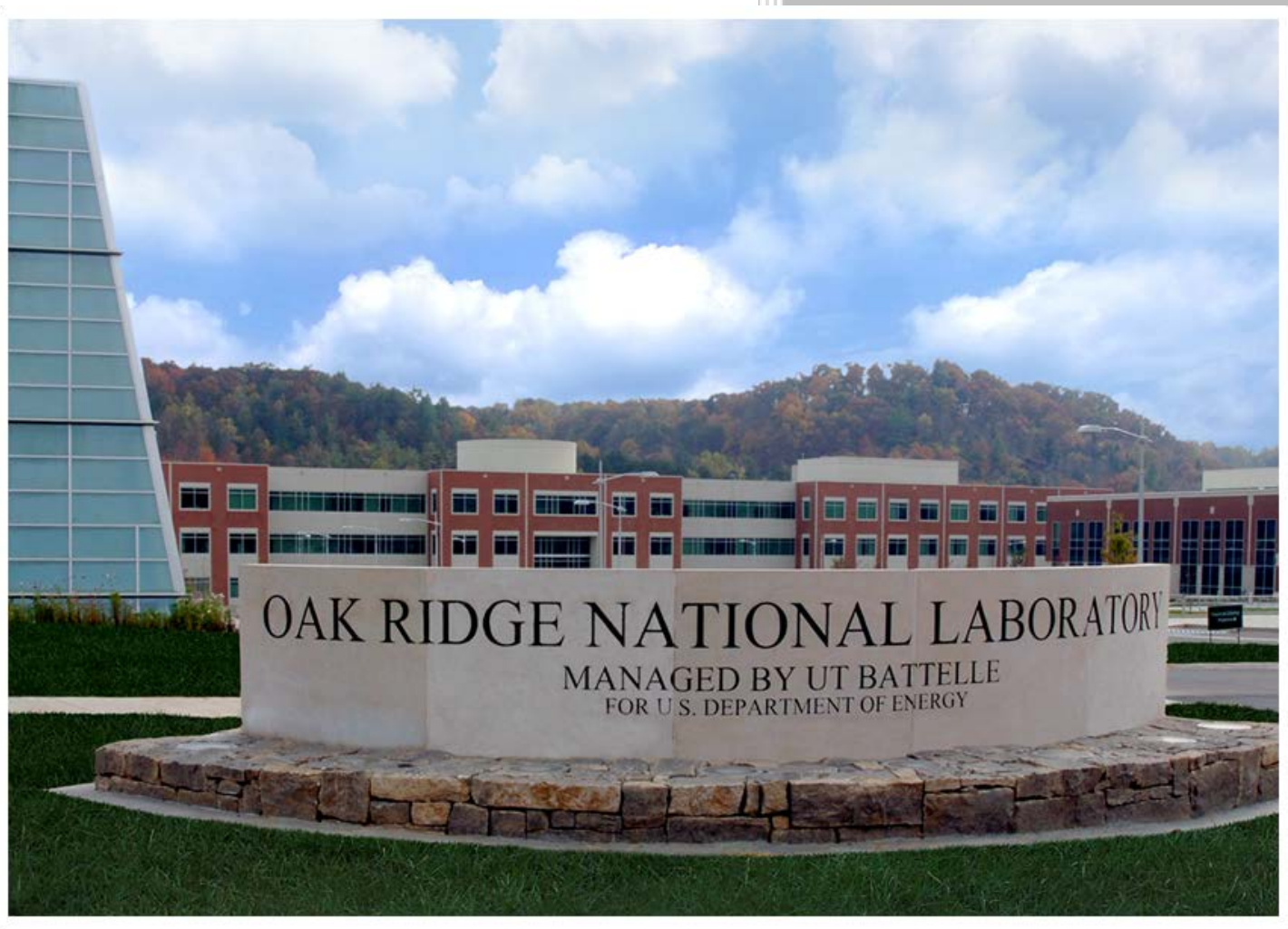

Niyanth Sridharan

September 09, 2016

CRADA FINAL REPORT NFE-16-06053

Approved for Public Release. Distribution is Unlimited. 


\title{
DOCUMENT AVAILABILITY
}

Reports produced after January 1, 1996, are generally available free via US Department of Energy (DOE) SciTech Connect.

Website http://www.osti.gov/scitech/

Reports produced before January 1, 1996, may be purchased by members of the public from the following source:

\author{
National Technical Information Service \\ 5285 Port Royal Road \\ Springfield, VA 22161 \\ Telephone 703-605-6000 (1-800-553-6847) \\ TDD 703-487-4639 \\ Fax 703-605-6900 \\ E-mail info@ntis.gov \\ Website http://www.ntis.gov/help/ordermethods.aspx
}

Reports are available to DOE employees, DOE contractors, Energy Technology Data Exchange representatives, and International Nuclear Information System representatives from the following source:

Office of Scientific and Technical Information

PO Box 62

Oak Ridge, TN 37831

Telephone 865-576-8401

Fax 865-576-5728

E-mail reports@osti.gov

Website http://www.osti.gov/contact.html

This report was prepared as an account of work sponsored by an agency of the United States Government. Neither the United States Government nor any agency thereof, nor any of their employees, makes any warranty, express or implied, or assumes any legal liability or responsibility for the accuracy, completeness, or usefulness of any information, apparatus, product, or process disclosed, or represents that its use would not infringe privately owned rights. Reference herein to any specific commercial product, process, or service by trade name, trademark, manufacturer, or otherwise, does not necessarily constitute or imply its endorsement, recommendation, or favoring by the United States Government or any agency thereof. The views and opinions of authors expressed herein do not necessarily state or reflect those of the United States Government or any agency thereof. 
ORNL/TM-2016/535

CRADA/ NFE-16-06053

Materials Science and Technology Division Advanced Manufacturing Office

DEVELOPMENT OF COATINGS FOR ULTRASONIC ADDITIVE MANUFACTURING SONOTRODE USING LASER DIRECT METAL DEPOSITION PROCESS

\author{
Authors \\ Niyanth Sridharan \\ Ryan. R. Dehoff \\ Brian Jordan \\ S. S. Babu
}

Date Published:

September 09, 2016

\author{
Prepared by \\ OAK RIDGE NATIONAL LABORATORY \\ Oak Ridge, Tennessee 37831-6283 \\ managed by \\ UT-BATTELLE, LLC \\ for the \\ US DEPARTMENT OF ENERGY \\ under contract DE-AC05-00OR22725
}

Approved For Public Release 


\section{CONTENTS}

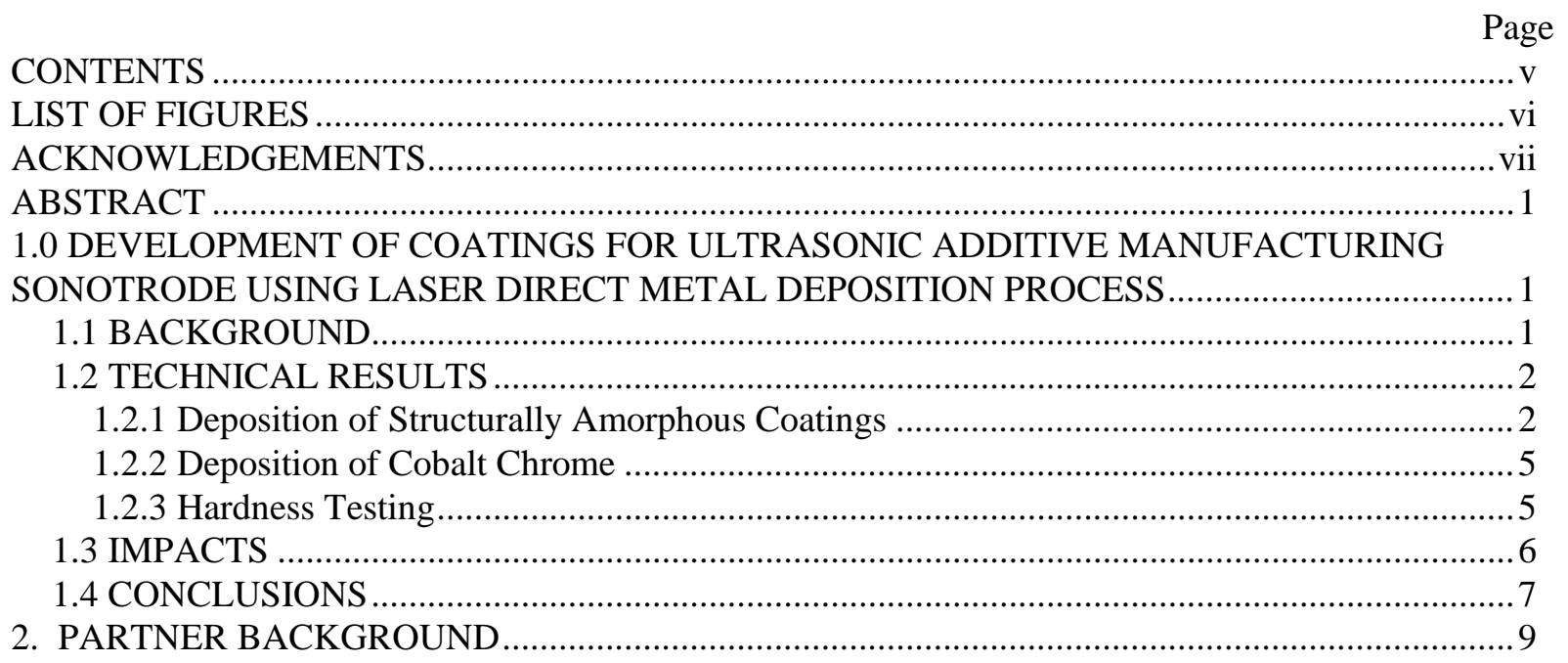




\section{LIST OF FIGURES}

Fig. 1. Shows the macroscopic images of the deposits fabricated using various tool paths and process parameters. Note the significant cracking in all of the samples.

Fig. 2. (a) Shows the optical micrograph outlining the cracks (b) Shows the microstructure at the interface with borides and the primary austenite (c) EDS map showing the enrichment of the $\mathrm{W}$ and $\mathrm{Cr}$ in the borides while the $\mathrm{Ni}$ content doesn't change between the matrix and precipitate as shown in the Scheil simulations which will be presented further.

Fig. 3. (a) Electron backscatter diffraction showing the crack propagating along the grain boundaries across the refined grains (b) Scheil solidification simulation performed using computational thermodynamics shows that the solidification range is greater than $300^{\circ} \mathrm{C}$ showing that the cracking mechanism could be attributed to solidification cracking.

Fig. 4. (a) Optical micrograph showing the deposit substrate interface that is free of cracks (b) Etched microstructure of the deposit showing the dendritic mode of solidification. The light etching regions are the borides and carbides responsible for the enhanced hardness of the alloy (c) Electron micrograph of the deposit material showing the interfaces between the borides and the matrix (d) EDS map showing the distribution of $\mathrm{W}$ in the deposit material. Note the significant partitioning of $\mathrm{W}$ into the boride phases.

Fig. 5. (a) Optical micrograph showing the deposit substrate interface that is free of cracks (b) Optical micrograph of the deposit showing a defect free deposit (c) Electron micrograph of the deposit material showing the dendritic mode of solidification (d) EBSD inverse pole figure (e) Phase map showing that the build solidified completely as a FCC material without the presence of any HCP............................ 5 Fig.6. (a) Micro hardness measurements of the stainless SAM (b) Micro hardness measurements of the

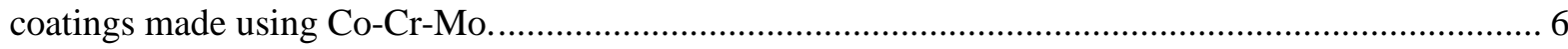




\section{ACKNOWLEDGEMENTS}

This CRADA NFE-16-06053 was conducted as a Technical Collaboration project within the Oak Ridge National Laboratory (ORNL) Manufacturing Demonstration Facility (MDF) sponsored by the US Department of Energy Advanced Manufacturing Office (CPS Agreement Number 24761).

Opportunities for MDF technical collaborations are listed in the announcement "Manufacturing Demonstration Facility Technology Collaborations for US Manufacturers in Advanced Manufacturing and Materials Technologies” posted at http://web.ornl.gov/sci/manufacturing/docs/FBO-ORNL-MDF2013-2.pdf. The goal of technical collaborations is to engage industry partners to participate in shortterm, collaborative projects within the Manufacturing Demonstration Facility (MDF) to assess applicability and of new energy efficient manufacturing technologies. Research sponsored by the U.S. Department of Energy, Office of Energy Efficiency and Renewable Energy, Advanced Manufacturing Office, under contract DE-AC05-00OR22725 with UT-Battelle, LLC. 


\begin{abstract}
ORNL partnered with Fabrisonic, LLC to develop galling resistant hard facing coatings on sonotrodes used to fabricate 3D printed materials using ultrasonic additive manufacturing. The development and deployment of a coated sonotrode is expected to push the existing state of the art to facilitate the solidstate additive manufacturing of hard steels and titanium alloys. To this effect a structurally amorphous stainless steel material and cobalt chrome material were deposited on the sonotrode material. Both the deposits showed good adhesion to the substrate. The coatings made using the structurally amorphous steel materials showed cracking during the initial trials and cracking was eliminated by deposition on a preheated substrate. Both the coatings show hardness in excess of $600 \mathrm{HVN}$. Thus the phase 1 of this project has been used to identify suitable materials to use to coat the sonotrode. Despite the fact that successful deposits were obtained, the coatings need to be evaluated by performing detailed galling tests at various temperatures. In addition field tests are also necessary to test the stability of these coatings in a high cycle ultrasonic vibration mode. If awarded, phase 2 of the project would be used to optimize the composition of the deposit material to maximize galling resistance. The industrial partner would then use the coated sonotrode to fabricate builds made of austenitic stainless steel to test the viability of using a coated sonotrode.
\end{abstract}

\title{
1.0 DEVELOPMENT OF COATINGS FOR ULTRASONIC ADDITIVE MANUFACTURING SONOTRODE USING LASER DIRECT METAL DEPOSITION PROCESS
}

This phase 1 technical collaboration project (MDF-TC-2016-037) was begun on February 1, 2016 and was completed on September 02, 2016. The collaborating industry partner Fabrisonic, LLC is a small business. Results from Phase 1 show that significant improvement in the performance of the sonotrode could be achieved with further research to optimize the process parameters and microstructure.

\subsection{BACKGROUND}

The ultrasonic additive manufacturing (UAM) process involves building up solid metal objects through ultrasonically welding a succession of metal tapes into a three-dimensional shape, with periodic machining operations to create the detailed features of the resultant object ${ }^{1}$. The ultrasonic vibrations generated by the transducer are transmitted, through the booster section, to the disk-shaped welding horn, which in turn creates an ultrasonic solid-state weld between the thin metal tape and base plate ${ }^{2-4}$. The continuous rolling of the horn over the plate welds the entire tape to the plate. This is the essential building block of UAM. It is to be noted that the "horn" shown in Figure 1(a) is a single, solid piece of metal that must be acoustically designed, so that it resonates at the ultrasonic frequency of the system (typically at $20 \mathrm{kHz}$ ).

The necessity of plastic deformation for the bond formation is well recognized in UAM ${ }^{5-7}$. To facilitate deformation in materials with high hardness it is necessary to use higher amplitudes and consequently operate the machine in the high power range. The problem that severely limits this technology is the "nuggeting" of the foils to the sonotrode. This leads to the frequent retexturing of the sonotrode to remove the nuggets, leading to a rise in operating costs and reduction in equipment time.

This "nuggeting" is a direct effect of galling, a wear mechanism involving transfer of material. Hence to improve the galling resistance of the sonotrode, this technical collaboration aims to develop and 
characterize suitable galling resistant coatings on the sonotrode. Previous efforts by the Fabrisonic to develop coatings were not successful, resulting in the delamination and cracking of the coatings. Hence the phase- 1 of this technical collaboration aimed to study the feasibility of using the directed energy deposition technique to fabricate coatings. A phase two of the project would then be initiated if the coatings show good adherence to the substrate, exhibit an increased hardness and are not prone to cracking. A coated sonotrode would help Fabrisonic to push the UAM technology even further to join hard materials. By leveraging the entire power range of the $9 \mathrm{~kW}$ UAM process it would be possible to fabricate dissimilar metal claddings in a much more energy efficient way.

Galling is a form of surface damage resulting in the degradation of surface quality, manifesting itself as damage in the surface ${ }^{8}$. Resistance to galling can be achieved by decreasing the total strain localization at the surface. This can be achieved by using a material with a high rate of strain hardening or by incorporating hardening precipitates in the material ${ }^{9}$. Previously ORNL developed hard facing alloys with a high percentage of boron, carbon and other boride forming elements .The largely amorphous powders then devitrify during solidification resulting in a nano crystalline matrix with a large fraction of borides resulting in a significant wear resistance. These coatings have already been deployed for various applications and are currently in service ${ }^{10}$. In a parallel effort in this project coatings using cobalt chrome will also be deposited. Cobalt based alloys generally have good galling resistance due to the face centered cubic (FCC) to hexagonal closest packed (HCP) phase transformation the alloy exhibits ${ }^{9}$. In this work the feasibility of depositing a defect free coating of stainless structurally amorphous metals (SAM) and Co-Cr-Mo alloy using the directed energy technique for fabrication of coatings will be explored.

\subsection{TECHNICAL RESULTS}

\subsubsection{Deposition of Structurally Amorphous Coatings}

The SAM powder with stainless composition was deposited using the Direct Metal Deposition DMD103D directed energy deposition process at the ORNL Manufacturing Demonstration (MDF) Facility. Initial trials were fabricated by changing the laser power travel speed and the tool path to optimize the deposition parameters. The results are summarized in figure-1(a-d).
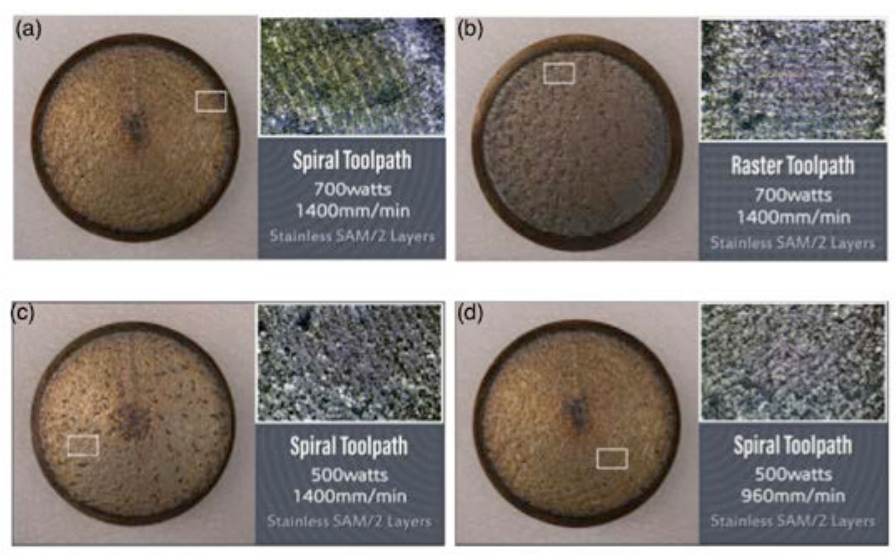

Fig. 1. Shows the macroscopic images of the deposits fabricated using various tool paths and process parameters. Note the significant cracking in all of the samples.

The initial deposits showed significant cracking in all the interfaces. Preliminary optical and electron microscopy does not show any difference in microstructure between the cracked and the uncracked 
regions as shown in figure 2. Figure-2(b) shows that the microstructure primarily consists of primary faceted borides, which solidified from the melt initially. The region adjacent the borides is depleted of alloying elements and consequently solidifies as a primary nano crystalline austenite as shown in figure-2(b). Notice that only W, Cr and Mo partition strongly to the boride phase while the $\mathrm{Ni}$ is retained in the austenitic phase as shown in figure 2(c). It is crucial to understand the as solidified microstructure since previous work has shown that the high wear resistance relies on the dispersion of the borides and the nano crystalline gamma phase. In addition, understanding the solidification mechanism could also offer interesting insights into the cracking mechanism.

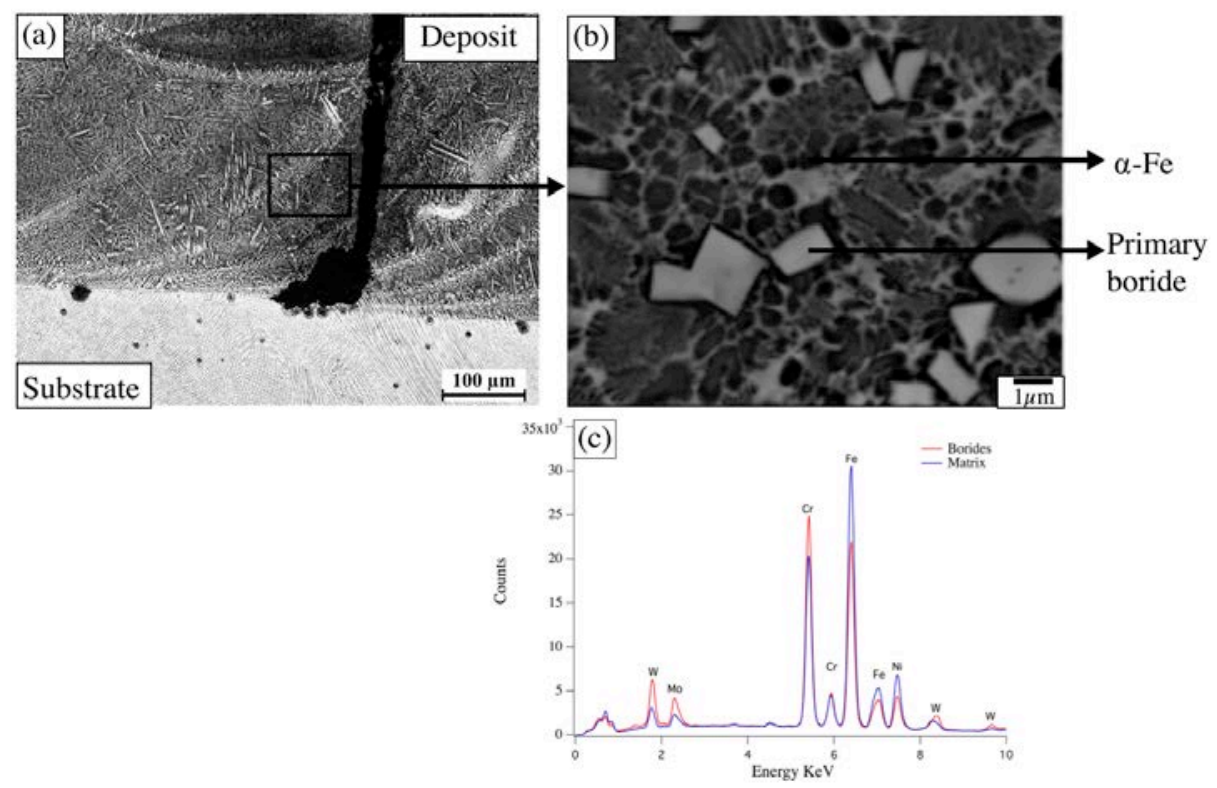

Fig. 2. (a) Shows the optical micrograph outlining the cracks (b) Shows the microstructure at the interface with borides and the primary austenite (c) EDS map showing the enrichment of the W and $\mathrm{Cr}$ in the borides while the Ni content doesn't change between the matrix and precipitate as shown in the Scheil simulations which will be presented further.

Electron backscatter diffraction was performed to rationalize the microstructure evolution and also understand the mechanism of solidification cracking. The result is shown in figure 3(a). Note that the cracks always proceed along the grain boundaries as shown in figure 3(a). This is a classic mechanism of how solidification cracking occurs. It is well known that the solidification cracking susceptibility increases with the increase in the solidification range. The higher the solidification range the liquid film wets the grain boundaries and embrittles them. The rapid cooling encountered during the solidification also acts as stress concentrators resulting in the tearing of the grain boundaries 11 . Scheil type solidification simulation was used to rationalize the solidification cracking mechanism to calculate the solidification range and also rationalize the microstructure evolution. The results are presented in figure-3(b). The figure shows that the solidification range is indeed large. In addition it also confirms the hypothesis on the microstructure evolution mechanism. 

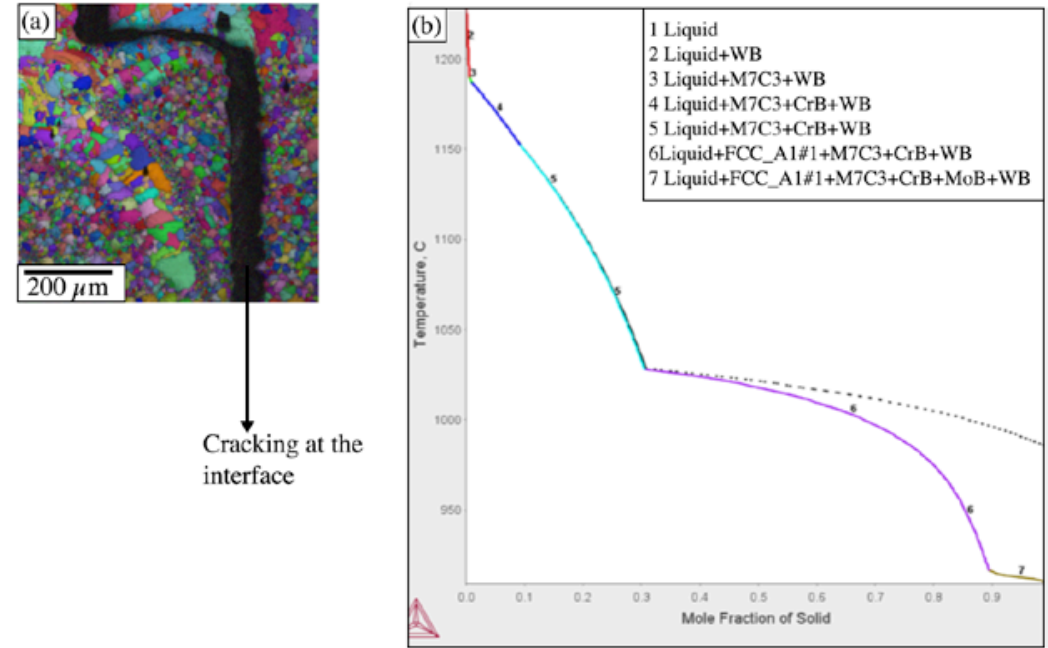

Fig. 3. (a) Electron backscatter diffraction showing the crack propagating along the grain boundaries across the refined grains (b) Scheil solidification simulation performed using computational thermodynamics shows that the solidification range is greater than $300^{\circ} \mathrm{C}$ showing that the cracking mechanism could be attributed to solidification cracking.

The susceptibility for solidification cracking is primarily related to the solidification range and shrinkage stresses. Hence cracking susceptibility can be reduced by either reducing the solidification range or by decreasing the shrinkage stresses. Since the solidification range is a strong function of the alloy composition. In the next set of builds the solidification shrinkage stresses were controlled by reducing the cooling rate by depositing on a substrate pre heated to $400^{\circ} \mathrm{C}$ substrate. The results of the second deposition are shown in figure 4 (a-c).
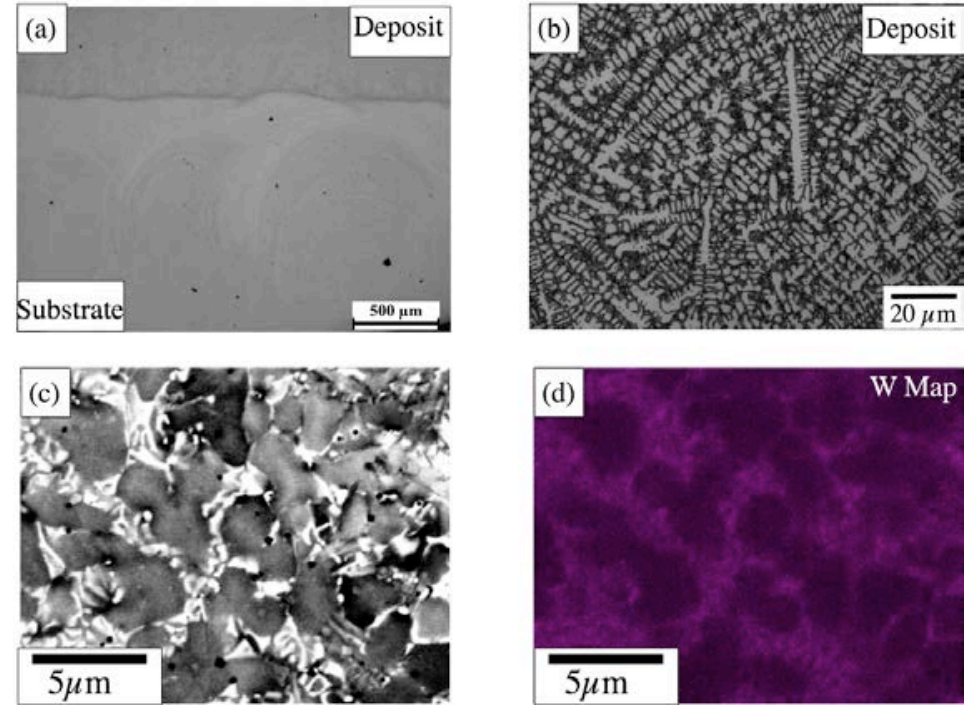

Fig. 4. (a) Optical micrograph showing the deposit substrate interface that is free of cracks (b) Etched microstructure of the deposit showing the dendritic mode of solidification. The light etching regions are the borides and carbides responsible for the enhanced hardness of the alloy (c) Electron micrograph of the deposit material showing the interfaces between the borides and the matrix (d) EDS map showing the distribution of $\mathrm{W}$ in the deposit material. Note the significant partitioning of $\mathrm{W}$ into the boride phases. 
From the results shown in figure 4, it is clear that by depositing on a pre heated substrate it is possible to reduce the shrinkage stresses by decreasing the cooling rate in the builds. The microstructure shows a high fraction of hard facing borides similar to what was observed previously. Hardness measurements using the Vickers hardness indenter showed that the hardness values in excess of 550 HVN were obtained, slightly higher than the substrate material. This shows the feasibility of using these coatings for future deployment. However it should be emphasized that before coating an actual sonotrode the galling resistance needs to be evaluated further. This would be done during the phase 2 of the work.

\subsubsection{Deposition of Cobalt Chrome}

Cobalt based alloys have been used extensively to combat galling in power plant applications. As mentioned previously the high galling resistance in Co based alloys relies on the strain induced FCC to HCP phase transformation. Hence in a parallel effort deposition of cobalt chrome was performed and the coating was characterized using similar techniques as used above. The deposition was performed on the substrate material of the sonotrode. The deposition was performed using a power of $500 \mathrm{~W}$ and $700 \mathrm{~mm} / \mathrm{min}$ travel speed and a powder flow rate of $7 \mathrm{~g} / \mathrm{min}$. Characterization of the coating using optical microscopy did not show any cracking or defects at the interface. The coating also exhibited good adherence with the substrate without the presence of any discontinuities at the interface as shown in figure 5 .
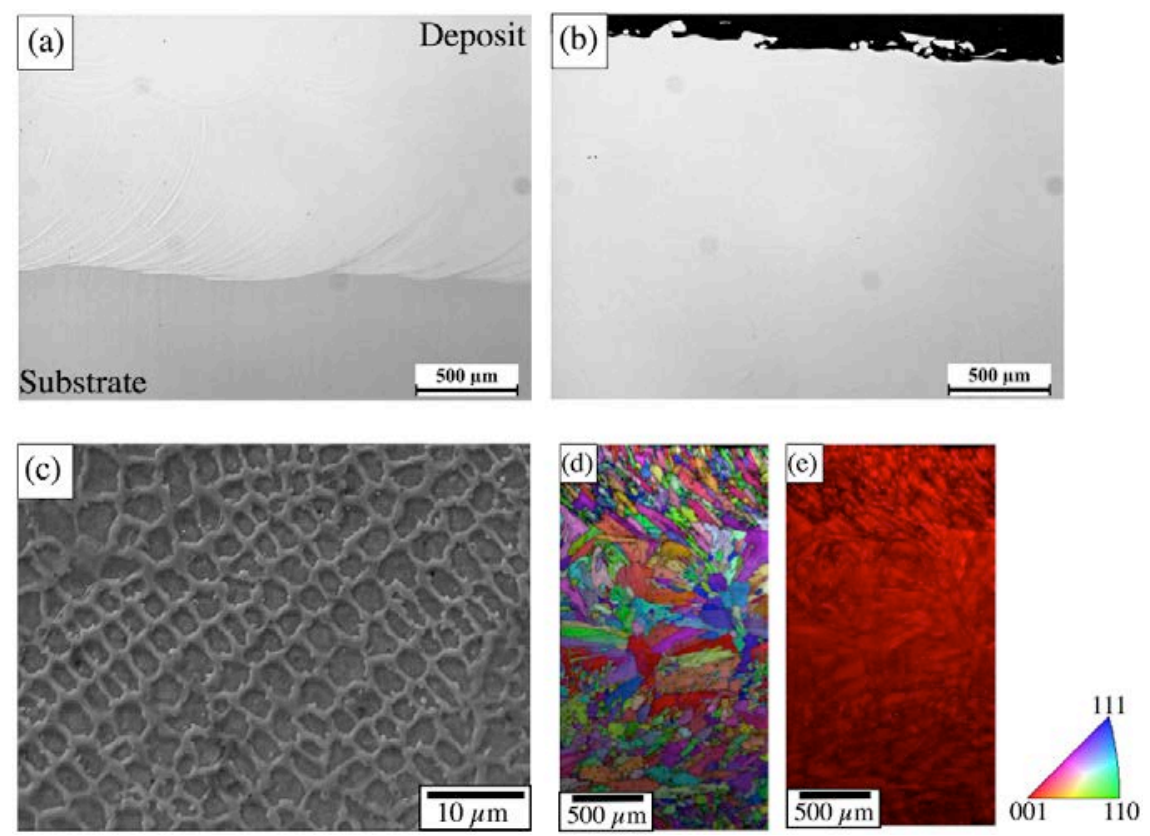

Fig. 5. (a) Optical micrograph showing the deposit substrate interface that is free of cracks (b) Optical micrograph of the deposit showing a defect free deposit (c) Electron micrograph of the deposit material showing the dendritic mode of solidification (d) EBSD inverse pole figure (e) Phase map showing that the build solidified completely as a FCC material without the presence of any HCP.

\subsubsection{Hardness Testing}

In this work the deposition of the stainless structurally amorphous material resulted in the increasing the fraction of hard carbides and the deposition of cobalt chrome would be expected to improve galling 
resistance by promoting a strain induced phase transformation. In general the galling resistance experiences a strong correlation to the hardness of the material. Hence hardness testing of the interfaces was performed. The hardness results of both the deposits are shown in figure 6 . It is clear that the deposit fabricated with the stainless SAM had a higher hardness almost 200 VHN higher than the cobalt chrome material.

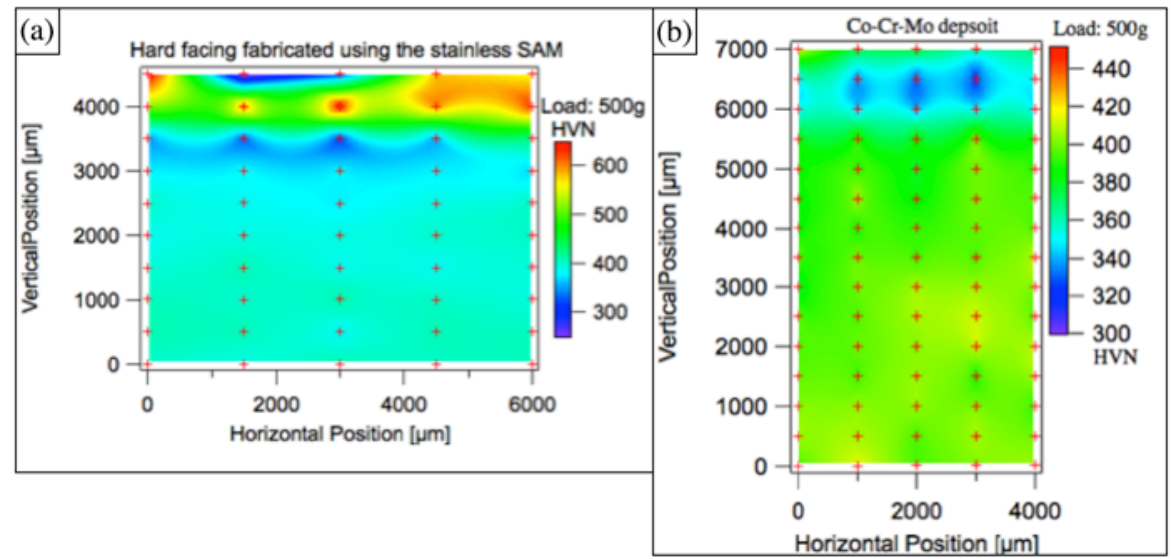

Fig.6. (a) Micro hardness measurements of the stainless SAM (b) Micro hardness measurements of the coatings made using Co-Cr-Mo.

Hence at this stage it is not clear as to which material is ideal to coat the sonotrode. A more detailed galling study is warranted to choose the ideal material to coat the sonotrode. If awarded, a phase two of the project would be used to optimize the compositions to maximize the galling resistance of the coating material followed by field evaluations of the coating.

\subsection{IMPACTS}

This work has demonstrated the potential of using the laser powder blown DMD system to develop galling resistant coatings on sonotrode tools used for ultrasonic additive manufacturing. A galling resistant coating on the sonotrode would affect a break through in the UAM technology in terms of the ability to fabricate hard materials and utilize the full potential of the system. At present the current technology is only able to fabricate soft FCC alloys such as aluminum alloys and copper alloys. As stated previously there is a major challenge in fabrication of hard materials due to the decreased galling resistance. This improvement in the sonotrode would help Fabrisonic to push the UAM technology to join hard materials. By leveraging the entire power range of the $9 \mathrm{~kW}$ UAM process hard material fabrication would be facilitated. This would be make it possible to fabricate dissimilar metal claddings in an energy efficient way.

The partner Fabrisonic has been closely working with the nuclear science user facility program at Oak Ridge National Laboratory with the aim of accelerating deployment of nuclear grade material fabricated using additive manufacturing. Fabrisonic has worked closely with ORNL in the past to use UAM to fabricate control rods for the high flux isotope reactor (HIFR) with a high degree of success. Due to the previous successes, there is a lot of interest in using solid-state additive manufacturing to fabricate austenitic alloys with embedded sensors for in pile data collection during irradiation of various austenitic alloys. In addition UAM is considered as a potential process to fabricate oxide dispersion strengthened Fe-Cr-Al alloys. However, at present the partner is limited in scope of fabricating these alloys due to the high hardness of these alloys. The major factor limiting deployment is the in sufficient galling resistance of the sonotrode. Hence a coated sonotrode would take the 
technology a long way in terms for fabrication of

1. Hard materials (Titanium alloys, Steels, Inconel)

2. Improve mechanical strengths of existing components by reducing the voids

\subsection{CONCLUSIONS}

As stated in the background section, the Phase1 goal of the project was to evaluate the feasibility of deposition of a defect free coating over the sonotrode material. To facilitate this objective feasibility studies were made using a structurally amorphous material having a stainless steel composition and cobalt chrome. Previously the partner has attempted to make such hard facings using a variety of processes but observed significant cracking and lack of adhesion between the coating and the substrate. This work has demonstrated that it is possible to fabricate coatings with good adhesion without any defects. Evaluating this work using the above metrics the team believes that with further research and development it may be able to accelerate the deployment of a coated sonotrode. It is however necessary to note that this breakthrough alone is not enough for commercial deployment of the sonotrode. There is significant more research and development required in terms of optimizing the coating thickness such that it offers sufficient galling resistance, and also has the resonance frequency at $20 \mathrm{kHz}$. In addition a series of galling tests at various temperatures and loads simulating the UAM process needs to be performed to evaluate the performance of these coatings before deployment. The sonotrode experiences significant increases in temperature locally during fabrication because of adiabatic heating. Consequently it becomes mandatory to evaluate the galling resistance of the coatings before actual deployment in the field. If the galling resistance is found to deteriorate with increases in temperature as documented in the literature, more work is required in terms of in situ alloying to prevent such deterioration. One way to improve the galling resistance further is by in-situ alloying the coating material with a high hardness ceramic such as tungsten carbide. Work along this space has been performed previously using the laser surface cladding technique but has however not been evaluated using the DMD process. These steps are necessary before final deployment of the sonotrode. A coated sonotrode is expected to benefit the partner industry and facilitate advanced manufacturing of functional parts with embedded sensors and claddings for use in the nuclear, automotive and aerospace industries. 


\section{PARTNER BACKGROUND}

Fabrisonic LLC is an innovative manufacturing technology company. The company provides equipment and services related to the patented Ultrasonic Additive Manufacturing (UAM) process which uses the sound waves to merge layers of metal foil. The process produces true metallurgical bonds with full density and works with a variety of metals such as aluminum, copper, stainless steel, and titanium. Using a combination of additive and subtractive processes, UAM can create deep slots, hollow, latticed, or honeycombed internal structures, and other complex geometries impossible with conventional subtractive manufacturing processes. Additionally, the solid state nature of the UAM bond allows for welding of dissimilar metals. This enables dissimilar metal cladding, production of custom metal matrix composites, and the ability to embed objects or sensors in a metal substrate. Through the use of UAM technology, customers will be able to manufacture complex parts that have unique features and attributes not possible using traditional manufacturing techniques. In addition, parts currently made with traditional operations can be made with much less waste, an increasingly important factor as more expensive, higher performance materials see broader use.

\section{REFERENCES}

1 Dehoff, R. \& Babu, S. Characterization of interfacial microstructures in 3003 aluminum alloy blocks fabricated by ultrasonic additive manufacturing. Acta Materialia 58, 4305-4315 (2010).

2 Graff, K., Short, M. \& Norfolk, M. in International Conference on Additive Manufacturing.

3 Schick, D. et al. Transient thermal response in ultrasonic additive manufacturing of aluminum 3003. Rapid Prototyping Journal 17, 369-379 (2011).

4 Sriraman, M., Babu, S. \& Short, M. Bonding characteristics during very high power ultrasonic additive manufacturing of copper. Scripta Materialia 62, 560-563 (2010).

5 Sridharan, N., Norfolk, M. \& Babu, S. S. Characterization of Steel-Ta Dissimilar Metal Builds Made Using Very High Power Ultrasonic Additive Manufacturing (VHP-UAM).

Metallurgical and Materials Transactions A 47, 2517-2528 (2016).

6 Sridharan, N., Wolcott, P., Dapino, M. \& Babu, S. Microstructure and texture evolution in aluminum and commercially pure titanium dissimilar welds fabricated using ultrasonic additive manufacturing. Scripta Materialia 117, 1-5 (2016).

$7 \quad$ Wolcott, P. et al. Characterisation of Al-Ti dissimilar material joints fabricated using ultrasonic additive manufacturing. Science and Technology of Welding and Joining, 1362171815Y. 0000000072 (2015).

8 Blau, P. J., Erdman Iii, D. L., Ohriner, E. \& Jolly, B. C. High-Temperature Galling Characteristics of TI-6AL-4V With and Without Surface Treatments. Tribology Transactions 54, 192-200 (2011).

9 Smith, R. T. et al. In situ X-ray diffraction analysis of strain-induced transformations in Feand Co-base hardfacing alloys. Scripta Materialia 98, 60-63 (2015).

10 Peter, W. H. et al. Application of Wear-Resistant, NanoComposite Coatings Produced from Iron-Based Glassy Powders. (Oak Ridge National Laboratory (ORNL); High Temperature Materials Laboratory, 2013). 
11 David, S., Siefert, J., DuPont, J. \& Shingledecker, J. Weldability and weld performance of candidate nickel base superalloys for advanced ultrasupercritical fossil power plants part I: fundamentals. Science and Technology of Welding and Joining 20, 532-552 (2015). 